\title{
INCREMENT BORINGS
}

\author{
By Geo. A. Mulloy
}

Dominion Forest Service

I $\mathrm{N}$ many studies of the rate of growth of stands by a single examination, increment borings have been the basis of the work. There are various methods of handling the data, the choice of method depending on the exact object of the investigation or the individual preference as to the method of applying the data to the stand or forest under consideration. The methods of taking the borings in the field, however, have been left more or less to chance, the only requirement having been that all the borings should be taken at breast-height and all diameter-classes should be represented. Errors arising from such factors as eccentric growth of the trees in radius or the selection of the part of the bole on which to make the boring were considered to be eliminated by averages.

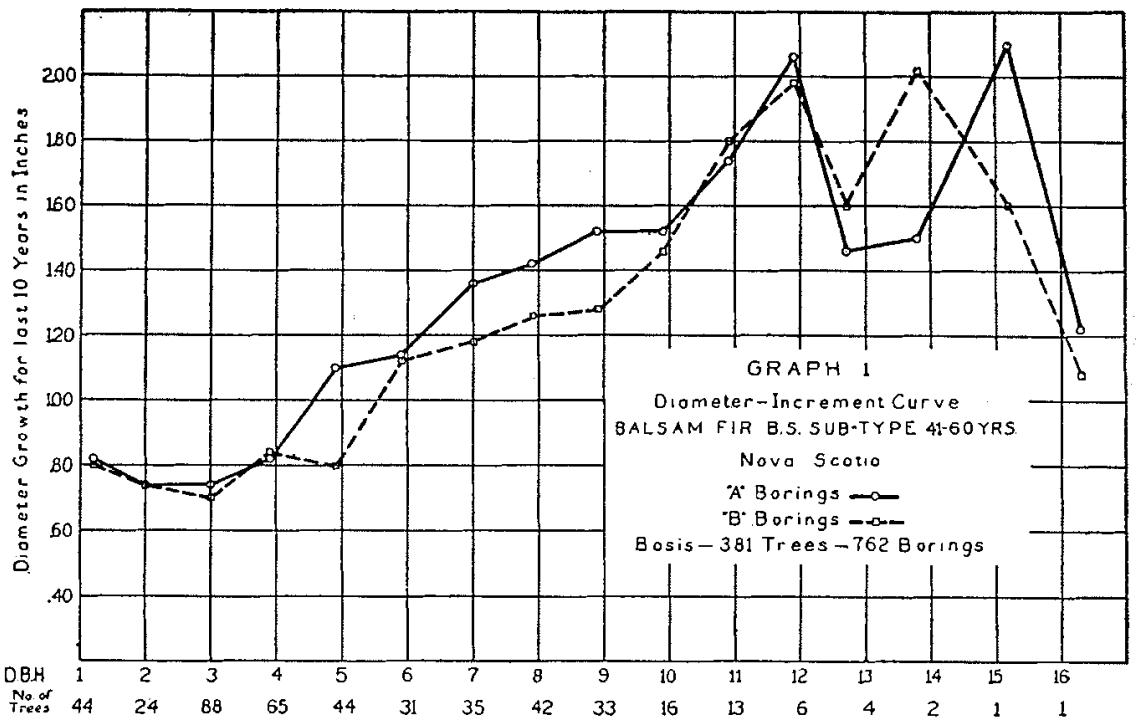

In connection with the rate-of-growth survey of Canada, now being carried on by the Forest Service of the Department of the Interior, a preliminary investigation on a small scale pointed to the possibility of error owing to eccentric growth of the trees selected for boring. When it is considered that, although a very large number of borings are taken, these are distributed among possibly ten sub-types, each of which is divided into six age-classes, and these age-classes again subdivided into 10 to 15 species, and each of these species again into 15 to 20 diameter-classes, it is apparent that the number of measurements in each diameter-class group, for which an aver- 
age is to be obtained, is necessarily small. There are certain species and subtypes of which this is especially true. Therefore, if there is a chance of a large consistent error, the average of the small amount of material in each diameter-class group cannot be depended upon to eliminate it.

For these reasons it was decided to make two borings in each tree sampled, one on either side of the tree. Although this had the effect of reducing the number of trees that could be bored in a given time, it was found that the two borings could be made in much less time than two borings on separate trees. Thus actually a larger number of samples were secured than if only one boring per tree were made. In recording the measurements of the icrement cores, the first boring was recorded separately from the second, and thus from the records of the rate-of-growth survey for the current year, an examination can be made of the effect of this method of taking increment borings.

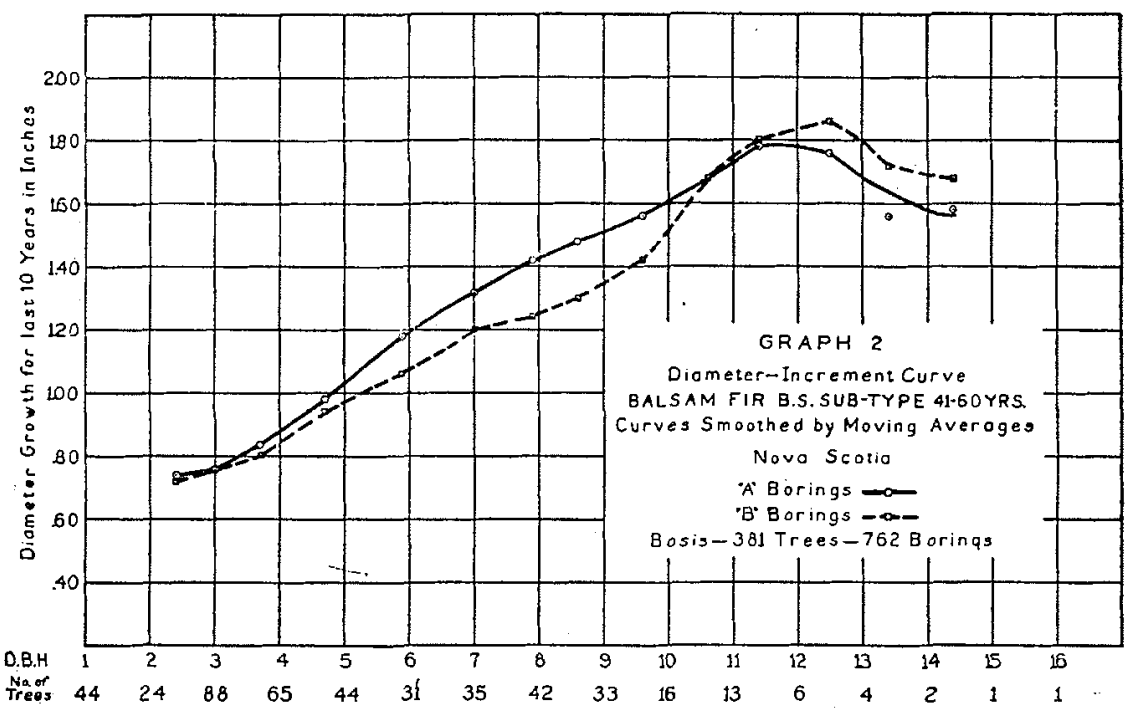

Accordingly, balsam fir from the balsam-spruce subtype, age-class 41 to 60 years, in Nova Scotia, was selected, as it was the most widely represented species in the most important type and age-class in that district. If it can be shown that the taking of two borings in each tree has eliminated any consistent gross errors in this single case, there is no need of proceeding with a further examination of other material merely to discover possibly more "horrible examples." The possibility of error will have been shown and the need of these measures to prevent similar errors.

In the remainder of the article the "number 1 " borings will be designated as " $A$ " borings and the "number 2 " borings as " $B$ " borings. 
The data from the " $\mathrm{A}$ " borings were separated from those for the " $\mathrm{B}$ " borings and the average radial and diameter increment for the last ten years was determined for each diameter-class. These data were then plotted and the points for each set of borings connected by lines so that the general trend of the two curves could be seen. Graph 1 shows these data. It is apparent that for a great section of the graph, namely, from four inches to ten inches, the two sets of data provide the basis for widely different curves. Moreover, in the upper diameter-classes, where few trees are represented, there is a very wide divergence. As smoothed curves are finally drawn for diameter. increment curves in the ordinary procedure, these have been drawn by the aid of floating averages (3's) and are shown in Graph 2. The two curves in this graph based on the two sets of measurements show more clearly how different are the respective bases of calculating volume increment.

As a demonstration of the effect of this variation, an average stand table in the balsam-spruce subtype, with an average volume curve, was selected and the present volume, volumes ten years ago, and the increment, have been calculated.

BALSAM-SPRUCE SUBTYPE

\begin{tabular}{c|c|c|c|c|c|c}
\hline \hline \begin{tabular}{c|c} 
D.B.H. \\
Inches
\end{tabular} & $\begin{array}{c}\text { No of } \\
\text { Trees }\end{array}$ & $\begin{array}{c}\text { Present } \\
\text { Vol. } \\
\text { Cu. Ft. }\end{array}$ & $\begin{array}{c}\text { Volumes 10 years ago } \\
\text { "A Boring } \\
\text { Cu. Ft. }\end{array}$ & $\begin{array}{c}\text { "B" Boring } \\
\text { Cu. Ft. }\end{array}$ & $\begin{array}{c}\text { Increment in 10 Yrs. } \\
\text { Cu. Ft. }\end{array}$ & $\begin{array}{c}\text { Boring Boring } \\
\text { Cu. Ft. }\end{array}$ \\
\hline 4 & 24.8 & 32.2 & 18.8 & 18.8 & 13.4 & 13.4 \\
5 & 18.6 & 44.6 & 24.2 & 26.0 & 20.4 & 18.6 \\
6 & 15.0 & 57.0 & 31.5 & 24.5 & 25.5 & 22.5 \\
7 & 9.1 & 51.9 & 30.1 & 31.8 & 21.8 & 20.1 \\
8 & 7.2 & 58.3 & 34.6 & 37.4 & 23.7 & 20.9 \\
9 & 4.4 & 47.1 & 29.9 & 32.1 & 17.2 & 15.0 \\
10 & 3.6 & 49.7 & 33.1 & 34.6 & 16.6 & 15.1 \\
11 & 1.1 & 19.1 & 12.9 & 12.9 & 6.2 & 6.2 \\
12 & .4 & 8.5 & 5.9 & 5.8 & 2.6 & 2.7 \\
13 & .2 & 5.1 & 3.7 & 3.6 & 1.4 & 1.5 \\
14 & .1 & 3.0 & 2.3 & 2.2 & .7 & .8 \\
15 & .1 & 3.6 & 2.8 & 2.7 & .8 & .9 \\
\hline
\end{tabular}

This table shows that the variation in the diameter-increment curves for the two sets of borings produces a difference of 12.6 cubic feet in the aggregate volume increment. Of course it may be argued that since the data from the " $\mathrm{A}$ " borings and the " $\mathrm{B}$ " borings will be averaged together (the differ- 
ence being consequently reduced to one half), the taking of all borings on separate trees may have resulted in the same curve. This would mean that twice the number of " $A$ " borings would have been taken and no " $B$ " borings.

In answer to this it may be pointed out that with the exception of some of the upper diameter classes the " $A$ " borings are in general larger than the " $B$ " borings. This seems to be rather an impossible condition and was at first not considered to be significant. But after an examination of the other material a general tendency was found for the " $A$ " boring to be larger than the " $B$ " boring. In consequence an examination of a large amount of material was made, including six different species and subtypes with 2754 borings. A tally was made in the case of each tree as to whether the " $A$ " or the " $B$ " borings was the larger. The result showed that out of the 1377 trees with two borings each, in the case of 721 trees the " $\mathrm{A}$ " boring was the larger, in 549 trees the "B" boring was the larger and in 107 cases the borings were of equal size. This proves that there is a distinct tendency for the " $\mathrm{A}$ " boring to be larger. It also proves that in the case of only one boring being taken, the resultant diameter-increment curve will be higher than the normal and consequently the volume increment will be higher than normal. Hence in the example given above had only one boring per tree been made, the diameter-increment curve would have followed, in all probability, the course of the curve of the " $A$ " borings.

The reason for the consistently higher measurements in the case of the "A" borings is obscure; but the following reasonable explanation may be taken for want of a better one. With the first boring taken on any tree, the side on which it is most convenient to work is first selected as would be done if only one boring were to be taken. The fact that the second boring, to be taken on the opposite side of the tree, may be in a difficult place to operate does not usually enter the operator's head, since the line of least resistance is followed. This results, in the majority of cases, in the first ("A") borings being taken on the side of the tree most open to the light and consequently growing faster in radius than the other side. This psychological effect upon the data is probably more operative in medium-sized dense groups, where the first borings would naturally be taken on the exposed side, than with older and more widely spaced trees.

Much of the other material examined did not show a wide variation between the increment curves for the two sets of borings, but this does not prove anything except that it cannot be foretold whether or not single borings on each tree will produce the same curve as double borings. If, as has been shown in the case of the most widely represented species in the largest subtype, such irregularities may occur, there is the possibility that very much larger variations may occur with other less widely represented species and types. It would seem the part of wisdom, then, to ensure that under, no 
circumstances will errors from this source be encountered. In any event, in the case of all diameter-increment curves, no matter on how much material they are based, there is bound to be a shortage of data in the upper diameterclasses; and if the trees in these classes happen to be of eccentric growth, a very misleading trend may be given to the end of the diameter-increment curves when only one boring per tree is made.

It is recommended, therefore, that in all rate-of-growth surveys, where the basis of calculating increment is a diameter-increment curve, two borings per tree, directly opposite each other, be made.

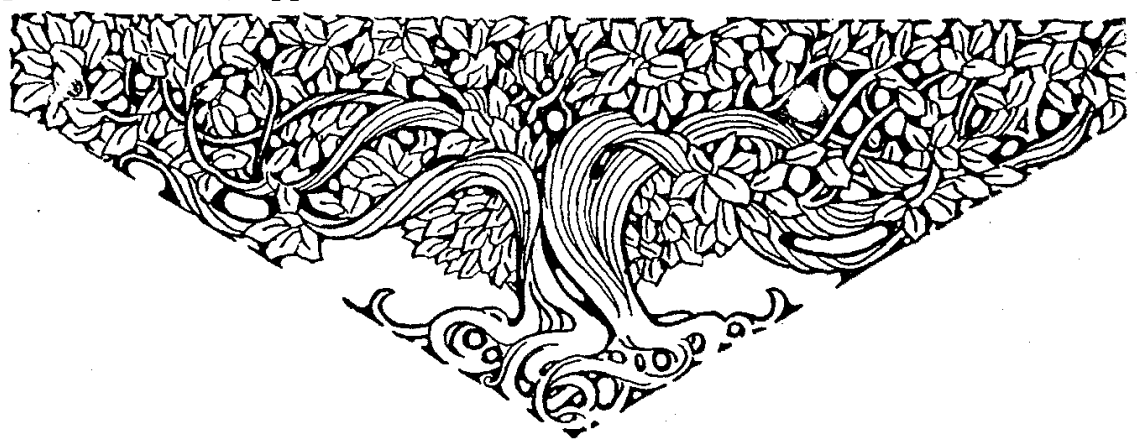

